\title{
SEDUÇÕES E RISCOS: A EXPERIÊNCIA DO MESTRADO PROFISSIONAL
}

\author{
Tânia Fischer \\ UFBA
}

\section{A SEDUÇÃO DO TEMA E OS RISCOS DA ABORDAGEM}

Fenômeno recente e polêmico no ensino de pós-graduação no Brasil, o mestrado profissional abre espaço entre as modalidades representadas por doutorado, mestrado acadêmico e especialização. Este texto é uma narrativa do processo de institucionalização do mestrado profissional (MP), iniciada nos anos 1990.

Viver a história e selecionar elementos para reorganizá-los dentro de um foco narrativo tem os riscos da mistificação dos fatos, mas também permite reconstruir trajetórias e, reflexivamente, olhar o futuro. Participei das formulações da política de ensino profissional, integrando comissões da Fundação CAPES e da Associação Nacional de Programas de Pós-Graduação em Administração (ANPAD) na década de 1990 e coordenei um dos quatro primeiros cursos de mestrado profissional durante seis anos e quatro turmas, totalizando 150 alunos ${ }^{1}$.

Este texto reflete sobre o MP como a inovação sedutora e arriscada que é. Tensões e dilemas têm marcado a trajetória desse modelo de ensino. As seduções ficam por conta dos esforços das instituições ao recriarem cursos de pós-graduação, investindo em novos designs curriculares e estratégias de aprendizagem, em quadros docentes com qualificação acadêmica e experiência gerencial, em bom ensino presencial e à distância, em conciliação de estudos com trabalho, em articulações efetuadas entre teoria e prática. Como se constata, o MP não é um curso excludente. Ao contrário, é ambicioso ao tentar conciliar os contrários, os paradoxos dos eixos acadêmico e profissional dos cursos de pósgraduação em Administração.

O percurso do ensino profissionalizante não foi tortuoso e ambíguo somente nas escolas brasileiras. A crise das escolas de gestão e as reações aos MBAs internacionais, vindas das instituições de ponta no exterior, tiveram como conseqüência a adoção de novos modelos e a internacionalização de cursos, com forte tendência à globalização.

Contextualiza-se o tema na história recente da pós-graduação brasileira, discutindo peculiaridades e paradoxos de uma área híbrida, com um pé no espaço acadêmico e outro nos espaços da sociedade regidos por lógicas diversas - sejam a empresa, os governos ou as organizações ditas sociais. Essa não é uma preocupação exclusiva da área de Administração. Hoje, há mestrados profissionais em áreas óbvias como Engenharia e Odontologia, mas também em Sociologia e Teologia. A mais surpreendente iniciativa é a dos mestrados profis- sionais em ensino de Física, Química e Matemática. Ou seja, antes de tudo, o mestrado profissional tem o caráter de inovação e reconstrução do modelo tradicional de ensino.

Revisitar o pretérito imperfeito, tanto na formulação de políticas quanto na realização de experiências, é o objetivo deste texto. Na segunda metade dos anos 1990, quatro instituições (duas universidades federais - UFBA e UFRGS - e as duas escolas de Administração da Fundação Getulio Vargas - EAESP e EBAPE) submetem projetos de mestrado profissional e os colocam em prática.

As lições aprendidas pela experiência da Escola de Administração da UFBA podem ser sumarizadas nos recursos de sedução utilizados e pelos elementos de risco e tensão que abarcam a experiência. Uns e outros podem ser relativamente estendidos aos outros cursos, todos embebidos no mesmo sistema institucional de pósgraduação fortemente centralizado e regulado pela Fundação CAPES, com direta participação da comunidade acadêmica.

Deste presente conturbado, surgem as questões finais deste texto. $\mathrm{O}$ que nos reserva o futuro volátil? Que seduções e riscos nos oferecerão as arenas institucionais? Há pistas sobre os percursos identitários dos cursos que formarão os gestores do futuro? 


\section{A GERAÇÃO DO MODELO DUAL DE PÓS-GRADUAÇÃO: UM PRETÉRITO IMPERFEITO?}

Desde o início, o sistema de pósgraduação vive uma espécie de síndrome bipolar, com dilemas e tensões entre os valores e critérios acadêmicos e as pressões do mundo do trabalho. Não por acaso, o mestrado profissional é alvo de polêmica da comunidade científica, aceito e rejeitado por instituições de peso, por representações e lideranças acadêmicas.

Vale lembrar que ele já estava previsto na regulamentação inicial da pósgraduação brasileira. O parecer $977 /$ 65 do Conselho Newton Sucupira, lavrado pelo então Conselho Federal de Educação, propunha a criação de cursos com orientação profissional. No entanto, desde a implantação, a pós-graduação visou ao atendimento da formação de professores e pesquisadores para a própria pós-graduação.

As décadas de 1960 e 1970 foram o momento dos investimentos na formação de pessoal, especialmente no exterior, e no apoio à implantação dos cursos de mestrado e ao início dos doutorados, como confirma a CAPES: "dentro dessa perspectiva, mesmo na fase em que os esforços se concentravam no aumento de nossa competência de formar mestres, a referência e grande meta da política de desenvolvimento da pós-graduação nacional foi a expansão da consolidação de cursos de doutorado acadêmico - nível em que se consubstancia o ideal da formação do pesquisador". Esperavase que os profissionais formados para a docência e a pesquisa tivessem papel "multiplicador", garantindo a formação de docentes e pesquisadores o que acabou acontecendo, ou seja, os programas de pós-graduação mimetizaram os programas internacionais que formam os professores no que estes têm de traços mais acadêmicos.
Os primeiros cursos acadêmicos de pós-graduação lato sensu iniciaram-se na década de 1960, e, na de 1970 , foram criados os primeiros mestrados. No entanto, a década de 1980 foi o momento da expansão. O sistema de avaliação da CAPES foi o elemento regulador e indutor dessa configuração: "Refletindo essa realidade, o Sistema de Avaliação da PósGraduação da CAPES foi concebido e estruturado para aferir o desempenho de programas e cursos voltados para a formação acadêmica, orientando-se, portanto, por parâmetros, critérios, indicadores e tipos de enfoque ajustados a tal propósito. A competência adquirida pela CAPES na avaliação da pós-graduação nacional foi, em conseqüência, calcada na realidade de programas e cursos vocacionais para a formação acadêmica".

Os anos 1990 foram tempos de diferenciação progressiva, ou seja, os cursos de especialização tiveram grande expansão, rotulados como MBAs, para efeitos de um mercado ávido por conhecimento e qualificação. Surge o mestrado profissional, de formato e denominação polêmicos, como o mais recente produto da expansão dos serviços de educação. Em 1993, as 50 instituições mais representativas do universo internacional de escolas, como Boconni, Harvard, Wharton, Insead e outras, reúnem-se em Paris para discutir a crise dos MBAs e propor novos modelos de ensino, bem como estratégias de internacionalização e parcerias para a conquista de novos e antigos territórios sul-americanos, africanos e asiáticos.

Em 1995, a CAPES cria um grupotarefa interdisciplinar para refletir sobre o modelo de pós-graduação e regular a criação de mestrados profissionais. Nesse grupo, como nos que se seguiram em 1998 e 2002, a área de Administração estava representada.
Desde a primeira resolução, o mestrado profissional foi concebido como um curso de natureza qualitativamente diferente, não como uma variante do mestrado acadêmico. As vertentes acadêmica e profissional, segundo a CAPES, são assim conceituadas:

$\checkmark$ a acadêmica - cujo propósito é formar pesquisadores, consubstancia-se na oferta do doutorado. Nessa vertente, cabe ao mestrado o papel de curso propedêutico, justificável nos casos em que essa etapa preparatória se revela necessária, face ao estágio de desenvolvimento da área de conhecimento no País ou em determinada região geográfica, ou para a superação de deficiências observadas na formação anterior dos alunos; e

$\checkmark$ a profissional - cujo objetivo é a formação de profissionais capacitados para o desempenho de funções outras que não a pesquisa acadêmica, mediante a oferta de cursos voltados para a aplicação, em um campo profissional definido, de conhecimentos e métodos científicos atualizados. O mestrado, neste caso, tem o caráter de curso terminal para a obtenção da habilitação pretendida.

Nas discussões pelo Conselho Superior, em 1995, sobre a necessidade de a pós-graduação brasileira diversificar-se para atender às novas demandas de nossa sociedade e definir as providências voltadas para esse objetivo, chegou-se à Portaria $n^{\circ} 47$, de 17/10/95, que determina a implantação pela CAPES de procedimentos apropriados a recomendação, acompanhamento e avaliação de cursos de mestrado orientados para a formação de caráter profissional.

A Portaria $n^{\circ} 80$, de 16/12/98, estabelece pressupostos e procedimentos para a recomendação, acompanhamento e avaliação de cursos de mestrado 
profissional. Em 15/09/1999, o Conselho Técnico Científico da CAPES aprova pressupostos para a avaliação de proposta do mestrado profissional. Em seguida, a resolução do Conselho Superior, em 12/11/2001, aprova as idéias básicas contidas nesse documento sobre o ajustamento do Sistema de Avaliação às necessidades de desenvolvimento da pós-graduação.

Verificou-se, a partir daí, o crescimento anual do número de propostas de cursos de mestrado profissional aprovadas pela CAPES: quatro em 1997, seis em 1998, 24 em 1999, 22 em 200025 em 2001, perfazendo 106 em 2002. Em 2002, novamente a CAPES retorna ao tema, constituindo uma comissão interdisciplinar para revisar as resoluções anteriores e propor uma política que defina a natureza dos cursos de mestrado profissional e estabeleça critérios de avaliação compatíveis.

A natureza desses cursos, segundo a CAPES, deveria ser expressa pelas seguintes características:

- Associação clara e direta da estrutura curricular, e das experiências profissionais oferecidas, às demandas atuais identificadas na sociedade ou, eventualmente, a serem induzidas. Isso envolve o desenvolvimento de mecanismos formais, para identificar tais necessidades e oportunidades, e mecanismos de avaliação, para assegurar a adequação de respostas às inevitáveis modificações de demanda ao longo do tempo.

- Construção do curso em torno de problemas do mundo real, a partir de interesses comuns entre o setor acadêmico e as instituições envolvidas - sejam empresas, instituições governamentais ou nãogovernamentais.

- Implantação e desenvolvimento do curso com o respaldo de esquemas eficientes de intercâmbio com a sociedade e instituições, no sentido de contribuir ao desenvolvimento de seus produtos e serviços, por um lado, e, por outro, melhor qualificar os estudantes.

O Mestrado Profissional nasce regulamentado. Dentro do conjunto de regras que o definem, estão claras as exigências de uma base de pesquisa, produção científica e técnica e corpo docente. Nos programas de pós-graduação já institucionalizados, essas condições existem e os mestrados profissionais têm seus títulos reconhecidos. No entanto, o mercado impôs sua lógica, e muitos cursos com formatos variados sob o rótulo de MBA e com níveis de qualidade heterogêneos são hoje oferecidos. A imprensa de negócios tem contribuído para a confusão entre bons e maus produtos, entre os cursos que dão certificados válidos e os que não têm qualidade nem são, ao menos, legais.

A pós-graduação em Administração tem, portanto, dois eixos: o acadêmico, com mestrados e doutorados que se assemelham aos cursos acadêmicos de outras áreas avaliadas pela CAPES, e o profissional, com mestrados profissionais e especialização (MBAs). Atualmente, a diversidade dos programas de pós-graduação (doutorados e mestrados acadêmicos versus mestrados profissionalizantes e especialização), bem como sua duração (em escola ou in company, presenciais ou à distância), criaram uma formidável dinâmica, em que as escolas contracenam com a sociedade com grande intensidade, provocando mudanças nas políticas de pesquisas e ensino.

Contudo, se os MBAs tiveram expansão descontrolada no final dos anos 1990, coincidindo com o maior crescimento dos cursos de graduação (quase 2 mil no início de 2003), o mesmo não ocorreu com o mestrado profissional. Revendo os números comparativamente a outras áreas, verifica-se que, no final de 2002, dos 106 mestrados profissionalizantes, 81 estavam em funcionamento e 25 tinham sido desativados.

O maior número de cursos de mestrado concentra-se na área interdisciplinar (15 cursos), seguida de Administração e Turismo com 13, Odontologia com 12 e Economia com nove. As outras áreas têm de um a três cursos. As instituições não foram tão agressivas na pós-graduação profissional stricto sensu quanto na especialização (leia-se MBAs) e na graduação. Sem dúvida, isso se deve à regulação da avaliação, que funciona como um mecanismo inibidor de experiências de má qualidade, mas não apenas delas. O desejo de reconhecimento acadêmico e a lógica da avaliação que incorpora com dificuldade as dimensões sociais do ensino e da pesquisa têm refreado a oferta de cursos assumidamente profissionais. Ou, então, cursos de excelente qualidade e impacto de mercado, de inequívoca natureza profissional, dizem-se acadêmicos e dispensam rótulos. Tal situação ocorre, principalmente, em instituições privadas, com cursos novos e não contaminados pelo passado.

As reações da comunidade acadêmica ao MP, encaminhadas ao Conselho Técnico da CAPES pelo Fórum de Pró-Reitores de Pós-Graduação e por representações de estudantes, são as seguintes:

- o MP poderia ser orientado por padrões de qualidade inferiores aos do mestrado acadêmico;

- o incremento do MP poderia reduzir a oferta de mestrados acadêmicos;

- os títulos do MP podem ser aceitos para ingresso na carreira docente.

No plano internacional, a crítica aos MBAs fortemente apoiados em 
áreas funcionais vem de todos os fronts: dos ortodoxos aos radicais críticos, das escolas tradicionais às mais recentes, por autores como Clegg, Colado \& Clarke, Mintzberg \& Gosling, Aktouf, Jynn Jr, Rodrigues e Fischer.

Os cursos mudaram nos últimos anos, e, mesmo os que continuam centrados em áreas funcionais, consideram fundamental capacitar para a gerência e desenvolver liderança. Ensinar a pensar, ética nos negócios, ênfase ao planejamento de carreira, comunicação e relacionamento são temas incorporados aos projetos de MBA. Os cursos são redesenhados, incorporando ensino interativo e atualizando o perfil do professor.

E no Brasil? Em meio à confusão pelo uso de sigla do MBA indistintamente a todo tipo de curso, o mestrado profissional torna-se uma realidade. Ainda mal compreendido e mal absorvido pela comunidade acadêmica, o curso está se desenhando como uma fusão entre os cursos acadêmicos e os MBAs. Mais sedutor que os cursos de MBA, pois permite, ironicamente, ensinar. Mas o que podemos aprender da recente experiência brasileira?

\section{LIÇÕES DE UMA EXPERIÊNCIA - FATORES DE SEDUÇÃO E RISCOS}

$\mathrm{O}$ que têm em comum gerentes de empresas como a Gerdau, a Ford, a Petrobrás e as Organizações Odebrecht, secretários de Estado, diretores da Caixa e gestores de ONGs, como o Projeto Tamar, e a Fundação Newton Rigue dos Shopping Iguatemi? O que os diferencia de alunos recém-egressos da graduação e de consultores, muitos deles ex-executivos?

$\mathrm{Na}$ sala de aula do mestrado profissional, todos buscam melhor qualificação como gestores. Querem um curso excelente em conteúdo e forma, sem falhas operacionais e que conci- lie a volta às aulas com o estresse da vida executiva. Viagens semanais, fusões, privatizações, conflitos de poder permanentes, competição. Em geral, a família também está em jogo. As expectativas são altas e a bagagem da maioria é apreciável. Além disso, participam de cursos e eventos no país e no exterior, lêem revistas de negócios e consomem a literatura dos gurus da administração.

Mas essa vida intensa não é o bastante. Ao retornar à academia, sinalizam para si próprios que querem mudar para se manter no emprego e para mudar de emprego - às vezes, de vida. É um choque a exigência do curso por tempo e energia já escassos.

$\mathrm{O}$ que seduz esses gestores e como a sedução se mantém ao longo de dois anos? Quais os riscos e dilemas desse projeto? O retrospecto do mestrado profissional da UFBA e a identificação dos fatores de sedução e de risco de tal experiência são uma tentativa de reflexão sobre processos em aberto e estratégias tateantes no campo do ensino.

\section{O contexto institucional}

Iniciou-se em 1996 a constituição do projeto MPA na Escola de Administração da UFBA, onde o programa de pós-graduação já tinha certa consolidação, quatro vezes avaliado com conceitos e nota máxima pela CAPES para a área.

Doutorado, mestrado acadêmico, programa de especialização, três núcleos de pesquisa, uma revista, produção docente e discente significativa. Instalações e infra-estrutura adequadas. Vontade de ousar e decisão institucional de inovar. Medos e reações institucionais generalizadas.

Começa-se a discutir um modelo de ensino diferenciado do convencional, no qual fatores de sedução foram previstos desde a concepção do design curricular, o que também ocorreu nas outras três experiências iniciadas naquela época por outras escolas.

O MP da UFBA, como os demais cursos, têm dimensões tangíveis que funcionam como "estruturas de superfície", tais como o design curricular, os planos de ensino, as estratégias docentes, o quadro de professores, as condições de apoio e infra-estrutura. No plano intangível: a marca e o prestígio institucional, a expectativa de aprendizagens significativas e de mudanças na vida e na carreira.

Alguns fatores de sedução:

- uso da marca e da imagem institucional. A escola atua há 50 anos e foi uma das pioneiras no ensino de Administração, juntamente com a UFRGS, a FGV-EAESP e a FGV-EBAP;

- adoção de princípios de flexibilidade, inovação, agilidade e consistência no design curricular e nas estratégias de aprendizagem;

- propostas de um perfil de gestão orientado para a multiqualificação, que permitisse ao participante migrar entre campos de gestão a partir do domínio de competência transversal básica, referenciais críticos e instrumentos;

- orientação a problemas concretos de gestão, ao prever estágio e um projeto de análise e intervenção organizacional como trabalho final;

- constituição de parcerias nacionais e internacionais para intercâmbio de professores;

- existência de um quadro docente reconhecidamente qualificado, ao qual se agregaram professores com experiência em áreas de aplicação, garantindo interdisciplinaridade e reflexões sobre práticas de gestão;

- estratégias de captação de recursos, garantindo sustentabilidade, pois o curso foi financiado por fundos públicos estaduais e federais como uma experiência em teste; 
- diversidade do alunato, selecionando-se gerentes das maiores e melhores empresas da região, lideranças do setor público e gestores do terceiro setor. A convivência dos opostos, no início difícil, tornou-se um dos grandes atrativos do curso. A ambiência de ensino é um espaço rico de experiências e complementaridade;

- avaliação sistemática e resultados por dois avaliadores internacionais, por comissões especiais da CAPES e pela Fundação Estadual de Pesquisa. Os resultados da primeira turma superaram os índices do país para mestrado $(60 \%$ de conclusões em 24 meses e $80 \%$ em 30 meses). O curso foi recomendado pela CAPES e obteve o conceito 5 na primeira avaliação;

- imagem projetada pelas revistas de negócios, em que foi destacado nos rankings nacionais por duas vezes, por jornais e em fóruns nacionais e internacionais.

Alguns fatores de risco:

- permanência como um curso inovador em época de transformações. Ser "metamorfose ambulante" é condição de sobrevivência, com o dilema de gerir a turbulência;

- legitimidade, para se manter dentro dos índices de produtividade, resguardando a consistência;

- sustentabilidade, mantendo adequada a relação entre captação e uso de recursos;

- visibilidade para sustentar a imagem construída e ampliá-la em tempos de concorrência exacerbada;

- reinvenção, pois todos os modelos de ensino são perecíveis e reinventá-los é uma arte de per- manente desconstrução e reconstrução.

As tensões e os dilemas associados a esses fatores de risco são problemas do cotidiano, de médio e longo prazo. A gestão é artesanal, com atenção aos detalhes, às sutilezas, aos matizes - mesmo em cursos com maior número de alunos.

Mas, se essa é uma experiência datada do final dos anos 1990, o que promete o futuro?

\section{FORMAR GESTORES EM UM FUTURO VOLÁTIL - DILEMAS E SEDUÇÕES NAS ARENAS INSTITUCIONAIS}

Nas organizações híbridas e multiculturais em que vivemos (e a academia é uma delas), a formação de gestores é uma tarefa sempre em aberto.

Um curso de mestrado é mais sedutor do que um MBA, uma especialização ou um programa breve de educação continuada. Há um título em jogo, há o prestígio da instituição que o concede, há a atração do desenho inovador, do quadro de professores, do alunato elitizado. Há também muitos dilemas e zonas de risco e tensão nas arenas institucionais.

São sedutoras as dimensões tangíveis e intangíveis de um curso que está mais próximo da sociedade e que deve ser desenhado a partir de demandas e requisitos externos, estabelecendo um perfil gerencial mais nítido. Tais cursos comportam novos designs curriculares, de natureza mais interdisciplinar e com formas mais criativas do que o tradicional serialismo disciplinar. Impõem-se a flexi- bilidade de formatos e o uso de metodologias mais ativas de ensino.

Um importante quesito é a relação teoria /prática. Não é sensato imaginar que alunos com experiência considerável em gestão venham buscar a prática de per si. Na verdade, a expectativa é de um espaço de aprendizagem no qual a experiência seja compartilhada e, de modo reflexivo, a teoria contribua para iluminar a prática. Isso é ainda mais verdadeiro no caso brasileiro, em que o alunato é mais maduro do que em outros países e a bagagem de que já dispõe é um importante recurso de ensino.

As exigências da sociedade por qualificação não vêm apenas da empresa, de governos ou do chamado terceiro setor. Organizações complexas, híbridas e multiculturais requerem multiqualificação.

No nosso pretérito imperfeito, o dilema foi formar acadêmicos ou gerentes em propostas de ensino excludentes entre si. No presente, existem fortes tensões entre modelos de ensino coexistentes nas mesmas arenas institucionais. O futuro é volátil; o mestrado profissional, uma espécie em mutação e um fascinante espaço de criação. Como um elo perdido, tem a responsabilidade de unir o mundo da academia e o mundo do trabalho, reduzindo tensões e dilemas da bipolaridade e mantendo acesa a chama da sedução.

\section{Nota}

${ }^{1}$ Foi um trabalho de criação coletiva de professores do NPGA - Núcleo de Pós-Graduação em Administração da Escola de Administração da UFBA. Entre outras pessoas que colaboraram com o projeto, destaco o prof. José Célio Andrade, atual coordenador do curso.

\section{Tânia Fischer}

Professora titular da Escola de Administração da UFBA e pesquisadora do CNPq E-mail: nepol@ufba.br 